\title{
Jornalismo na Era dos Testemunhos e as mudanças nas práticas jornalísticas no século XXI: o caso Lava Jato
}

\section{Journalism in the Age of Testimonies and Changes in Journalistic Practices in the 21st Century: the Lava Jato case}

\section{Cristine Gerk ${ }^{1}$}

Resumo: Este artigo pretende analisar as implicações nas práticas jornalísticas de um momento histórico marcado pela proeminência do testemunho. Um dos exemplos usados para esta análise é o tratamento midiático dado às delações da Operação Lava Jato, que tiveram impactos profundos no país, incluindo o impeachment da ex-presidente Dilma Rousseff. No artigo, analisa-se o tratamento dado a essas delações em matérias publicadas em sites de veículos da mídia hegemônica nacional e discute-se o papel dos relatos hoje. Para estes veículos, a exposição pública é considerada um serviço para a sociedade. Não há necessidade de procedimentos especiais para autorizar relatos, e o jornalista parece atuar como controlador de testemunhos alheios. Alguns autores que pesquisam este fenômeno, como Paulo Vaz, Muniz Sodré e Beatriz Sarlo, são inspirações teóricas para o estudo.

Palavras-chave: Jornalismo; Testemunho; Corrupção; Relato; Internet.

Abstract: This paper intends to analyze the implications of a phenomenon called "Journalism in the Age of Testimonies". One of the examples analyzed is the way the media handled the state's evidence turned during the Lava Jato Operation, which had profound impacts in Brazil, including the impeachment of the former president Dilma Rousseff. In this paper, we try to understand how these statements were presented in articles published in the websites of the largest hegemonic media vehicles and analyze the role of the accounts today. Public exposure is considered to be a service to society. There is no need for special procedures to authorize accounts and the journalists seem to act as controllers of the statements given. Some authors who research this phenomenon, such as Paulo Vaz, Muniz Sodré and Beatriz Sarlo, are theoretical inspirations for this study.

\footnotetext{
${ }^{1}$ Aluna do doutorado em Mídias e Mediações Socioculturais da Escola de Comunicação da Universidade Federal do Rio de Janeiro (ECO/UFRJ).
} 
Keywords: Journalism; State's Evidence; Memory; Statement; Internet.

\section{Introdução}

Desde a massificação do uso de redes sociais, a partir do início do século XXI, as práticas jornalísticas vêm sofrendo profundas transformações. Neste mar de mudanças, nos interessa, neste artigo, mergulhar em um aspecto de grande impacto e significado: o tratamento dedicado aos relatos no jornalismo. Partimos do pressuposto de que, se antes o jornalista se posicionava como observador da realidade, ele hoje parece perder lugar para um novo autor cada vez mais legitimado pela experiência. Ou seja, quanto mais tenha vivenciado a situação narrada, mais este novo autor vai parecer ser autêntico aos olhos do leitorespectador. E, atualmente, este canal de comunicação é facilitado pelas redes sociais e pelos smartphones, mecanismos que tornam possível e imediata a transmissão de experiências em qualquer lugar, a qualquer hora. Em outras palavras, não é possível desconsiderar que o jornalista sempre colheu relatos e testemunhos para produzir suas histórias. O que parece mudar são o tratamento e o lugar de destaque dados hoje ao relato puro, sem contexto ou confronto, bem como a profusão e agilidade de sua veiculação. O papel do jornalista como mediador parece perder um pouco do sentido na contemporaneidade (GERK, 2016), diante de uma nova configuração do tempo, que não permite o hiato necessário para a mediação.

Neste contexto, interessa usarmos como exemplo para análise os impactos da cobertura da operação Lava Jato, que nasceu no Brasil com a pretensão de unir a nação na bandeira do "combate à corrupção". A arma para ganhar estrelismo na guerra seria apenas uma: a fala. Enquanto a operação se tornava uma verdadeira indústria da delação, as engrenagens midiáticas trabalhavam a todo vapor, transformando imediatamente os relatos de denunciados e delatores em produtos para consumo rápido de massa. Pelas redes sociais, as falas de um ou outro político alimentavam discussões polarizadas, usadas como trunfos da verdade sobre as causas da crise política e encaradas como provas para argumentos pró ou contra o partido da presidente.

Este artigo pretende analisar algumas implicações nas práticas jornalísticas deste fenômeno batizado de "Jornalismo na Era dos Testemunhos", usando como exemplo o tratamento midiático dado às delações da Lava Jato, que tiveram impactos profundos no país, em uma onda acusatória que teve como ápice o impeachment da então presidente Dilma

${ }^{2}$ Este conceito de "Jornalismo na Era dos Testemunhos" começou a ser desenvolvido na dissertação de mestrado de C. GERK (2016) e segue sendo desenvolvido com maior profundidade na tese de doutorado da autora. 
Rousseff, ainda que em diferente contexto. Nos sites dos maiores veículos da mídia hegemônica nacional, as matérias tinham como padrão a simples reprodução do relato, sem haver, na maioria dos casos, preocupação com a contextualização da informação, pela pressa de veiculação das falas.

A Lava Jato é um conjunto de investigações conduzidas pela Polícia Federal do Brasil, que cumpriu mais de mil mandados de busca e apreensão, de prisão temporária, de prisão preventiva e de condução coercitiva, no bojo da apuração de um esquema de lavagem de dinheiro que teria movimentado bilhões de reais em propina. A operação começou em 17 de março de 2014, conduzida pelo então juiz Sergio Moro, quando a ex-presidente Dilma Rousseff (PT) ainda estava no poder. As eleições de 2014 foram marcadas por uma disputa acirrada entre os partidos PT e PSDB. Após a vitória de Dilma (51,64\% dos votos no segundo turno), o candidato derrotado, Aécio Neves, liderou diferentes ações visando à criminalização da chapa vencedora.

O processo de abertura de impeachment foi aceito no dia 2 de dezembro de 2016 pelo então presidente da Câmara dos Deputados do Brasil, Eduardo Cunha. O pedido acusava a presidente de ter cometido as chamadas "pedaladas fiscais", operações contábeis do Tesouro Nacional com a intenção de atrasar, de forma proposital, o repasse de dinheiro para bancos e autarquias, o que foi interpretado como crime de responsabilidade. Mas, nas ruas, a grande adesão popular à derrubada da presidente tinha como bandeira o combate à corrupção, na ordem do dia. Os deputados aprovaram o pedido no dia 17 de abril, em sessão transmitida ao vivo na televisão. No Senado, a votação aconteceu no dia 12 de maio. O senador Antonio Anastasia, do PSDB, partido de oposição ao governo Dilma, foi o relator do processo. Dilma foi afastada por 180 dias e o vice-presidente, Michel Temer, assumiu interinamente a presidência da República. Na votação final do impeachment, em 31 de agosto, Dilma foi definitivamente afastada, com 59 votos a favor e 21 contra. Apesar da cassação, ela manteve a elegibilidade.

Ao longo de todo este processo, as falas que vazavam na mídia, independentemente de contundente autorização judicial, ganhavam repercussão instantânea. Áudios particulares da então presidente conversando com o ex-presidente Luiz Inácio Lula da Silva foram amplamente divulgados, antes de serem analisadas profundamente as implicações políticas e a legalidade da divulgação. A conversa do ex-presidente da Transpetro Sergio Machado com o senador licenciado Romero Jucá, sobre a necessidade de deter o avanço da operação de combate à corrupção com a derrubada de Dilma em um "grande acordo nacional", também foi muito comentada nos meios de comunicação. Os vídeos com as delações de executivos da 
empresa Odebrecht à operação geraram uma verdadeira corrida de jornalistas ao furo de reportagem, sem necessidade de tratamento ou interpretação, sobretudo em um primeiro momento.

Esse último caso, que ocorreu já no governo de Michel Temer, vale uma análise mais prolongada, pois é bem emblemático no que tange às reflexões propostas neste artigo. É justamente dele que falaremos na próxima seção. Enquanto isso, interessa pensar um pouco mais a respeito deste fenômeno atual da proliferação de testemunhos, para que possamos estabelecer alguns conceitos antes da discussão. Segundo Vaz, Santos e Andrade (2014), passamos hoje de um cenário em que se privilegiava a confissão - forma de discurso autobiográfico decisiva para a constituição da subjetividade desde, ao menos, o Concílio de Trento até a modernidade - para uma era de testemunhos, o novo discurso autobiográfico crucial para a produção da subjetividade contemporânea. Neste contexto, o interlocutor deixa de ser valorizado por ter autoridade e ser capaz de ajudar em um processo secreto de salvação ou cura. Ele passa a ocupar um lugar de duplo endereçamento. Quem escuta é um indivíduo qualquer, tolerante e solidário, em uma dinâmica terapêutica que pressupõe a ida ao espaço público, e não o segredo. A exposição pública é considerada um serviço para a sociedade. Mesmo quando não se trata da fala de vítimas, ou seja, quando há um testemunho de alguém acusado por um crime, como no caso da Operação Lava Jato, há uma valorização da divulgação imediata das falas, nessa defesa da importância da exposição pública como serviço à sociedade, sem necessariamente a preocupação por uma maior contextualização ou apuração das informações que envolvem as afirmações em questão. No caso da Lava Jato, não são necessariamente os delatores ou delatados que vêm a público expor suas narrativas, já que eles não têm controle do uso público de suas falas. Mas o uso público destas falas precisa ser entendido dentro de um contexto atual de valorização da divulgação de testemunhos e da forma como passam a ser recebidos sem necessidade de uma mediação prévia, que teria supostamente, em um entendimento histórico, papel esclarecedor e de aprofundamento.

De acordo com Vaz, Santos e Andrade (2014), o silêncio, quando ocorre hoje, é provocado pelo julgamento moral da sociedade ou a imposição de um algoz. Uma cultura que concede preeminência à forma narrativa "sem dúvida não tem mais necessidade de procedimentos especiais para autorizar seus relatos" (LYOTARD, 1986, p. 41), tampouco sua divulgação. Sem necessidade de recorrer a uma argumentação mais profunda ou à administração de provas, o testemunho valorizado é cheio de fatos bem descritos, que dão dimensão realista à narrativa (SARLO, 2007, p. 50). 
O jornalista parece atuar como uma espécie de controlador de testemunhos alheios. Jean de La Bruyère (1847) definiu que "le contraire des bruits qui courent des affaires ou des personnes est souvent la vérité"3. Tentar revelar essa "verdade" seria o papel do jornalista clássico, a partir de sua autoridade moral. Porém, o grande número de relatos parecidos, circulando hoje na internet, rotineiramente passa a ser sinal de que algo é verdadeiro. O lugar da fofoca é revisto e ressignificado. A fofoca passa a ser a notícia, é outro critério de estabelecimento da verdade, cada vez menos investigada ou perseguida, mesmo se considerarmos que não existe uma verdade absoluta. $\mathrm{O}$ antídoto para esse deslocamento no papel do jornalista-testemunha, segundo a proposta de Sodré (2009), estaria na qualidade da notícia garantida pelo estatuto jornalístico, devendo a imprensa ter a capacidade de complementar as informações. Mas nem sempre esse ideal é perseguido, quando se favorece uma mera administração de relatos nos textos jornalísticos.

O jornalista sempre trabalhou a partir de falas, relatos ou entrevistas. O que se discute atualmente são os impactos de mudanças nas práticas diárias que alteram o trato dado a essas afirmações, sobretudo para atender uma demanda de grande velocidade. Com menor ida a campo e tempo para investigações aprofundadas, o jornalista tem menos condições de produzir textos que levem mais em consideração o contexto e as relações históricas. Com a agilidade cobrada, perde-se, com frequência, uma maior possibilidade de articulação dos fatos, de verificação da veracidade ou da confiabilidade dos depoimentos, ou mesmo de uso do recurso do contraditório ou de uma maior diversidade de opiniões e pontos de vista sobre um mesmo fenômeno.

Esta preocupação é manifestada pelos próprios jornalistas brasileiros. Pelas redes sociais, circulam testemunhos de todo tipo, compartilhados sem necessariamente importar a preocupação com a fonte e com outras versões envolvidas. Essa característica presente na experiência - de que ela mesma produz a verdade vivida - está também de maneira exponencial em vídeos e fotos mandados pelos leitores para jornais e sites e reproduzidos em produtos jornalísticos. Em entrevista à autora, jornalistas da redação do jornal Extra, da Infoglobo ${ }^{4}$, alertaram para o perigo da prática, cada vez mais frequente na mídia como um todo, segundo eles, de produzir matérias apenas a partir de um relato enviado por leitores por

\footnotetext{
3 "O contrário dos boatos que correm sobre acontecimentos e pessoas é frequentemente a verdade" (DE LA BRUYĖRE, 1847, tradução nossa).

${ }^{4} \mathrm{Na}$ dissertação intitulada Jornalismo e público: reconfigurações no contexto digital. WhatsApp do Extra como ferramenta histórico-tecnológica (2016), dez jornalistas do jornal Extra relataram ser comum a prática de produzir matérias apenas a partir de uma única mensagem enviada por uma vítima pela rede social.
} 
meio de redes sociais, como o WhatsApp, sendo o leitor a fonte da informação. Mensagens acompanhadas de fotos ou vídeos têm mais chances de virarem instantaneamente matérias. É a verdade da experiência de cada um, transmutada sob a forma de imagens vistas, capturadas e partilhadas, que produz um discurso desassociado de qualquer referencial, tendo nele mesmo o sentido exacerbado do verdadeiro. É a experiência da fonte que é transportada via mecanismos comunicacionais, sendo ela, muitas vezes, isenta da dúvida, de questionamentos e investida do efeito verdade apriorístico.

Se antes o jornalista se posicionava como observador da realidade, ele hoje perde lugar para um novo autor cada vez mais legitimado pela experiência. Ou seja, quanto mais tenha vivenciado a situação narrada, mais o autor do relato vai parecer ser autêntico aos olhos do leitor-espectador. E atualmente este canal de comunicação é facilitado pelas redes sociais e pelos smartphones, mecanismos que tornam possível e imediata a transmissão de experiências em qualquer lugar, a qualquer hora.

O espectador é tocado por imagens e relatos emotivos de acontecimentos tão intensos quanto breves, o que faz com que ele viva oscilando entre a indignação e a simpatia, sem espaço ou tempo para reflexão e compreensão. Como alerta d'Amaral (2010, p. 78), "se é no testemunho que muitas vezes o jornalismo se humaniza, também é por intermédio dele que se pode espetacularizar ou descontextualizar um relato jornalístico".

Fonseca e Kuhn (2009) lembram que o conhecimento produzido pelo jornalismo é mais facilmente assimilável pelo público do que o produzido por especialistas. Assim, o discurso de pessoas comuns nos meios de comunicação pode estar ocupando cada vez mais o estatuto de verdade antes relegado a especialistas. Entretanto, como qualquer forma de conhecimento, o produzido pelo jornalismo é condicionado histórica e culturalmente pelo contexto e subjetivamente pelos que participam da produção. Mas a notícia é apresentada como se fosse a realidade, sobretudo se legitimada por recursos audiovisuais e relatos. $\mathrm{O}$ público não tem acesso aos critérios de relevância que ajudaram o jornalista a construir essa versão da realidade.

Sarlo (2007) critica o testemunho como um lugar inquestionável na narrativa e, portanto, protegido do ceticismo e da visão crítica. Quando transportado para um texto jornalístico, esse testemunho estabelece novas relações morais e desloca o observador para personagem principal com perspectiva de autoridade, afastando as desconfianças, esquecendo-se dos "atos de memória" e de que só é retratado um lado da história. É a crise do que Zelizer (1992, p. 2-3) definiu como a questão central que dá ao jornalista autorização e credibilidade para ter um enunciado especial sobre os acontecimentos: a crença popular que 
os investe de autoridade, reconhecidos como observadores acreditáveis no mundo real, constituindo uma autoridade cultural.

\section{Análise empírica do fenômeno}

No correr da reflexão sobre esse fenômeno, interessa avaliar o tratamento dado a testemunhos da Operação Lava Jato, que envolvem, com frequência, falas de pessoas que se autointitulam vítimas de complôs ou calúnias e acusam outros em seus relatos. Um momento da operação é marcante neste sentido. Os depoimentos dos 78 delatores da construtora Odebrecht, que firmaram delação premiada com a Justiça Federal no âmbito das investigações da Lava Jato, foram liberados à imprensa no dia 11 de abril de 2017, pelo ministro Luiz Edson Fachin, relator da operação no Supremo Tribunal Federal. Com base nessas delações, o STF acolheu parte dos pedidos de abertura de investigação feitos pelo então Procurador-Geral da República, Rodrigo Janot, e determinou a instauração de inquéritos para investigar ministros, senadores e deputados do Governo Michel Temer. Em 12 de abril, o então juiz federal Sergio Moro seguiu a mesma linha do Supremo e retirou o sigilo das delações que envolviam pessoas sem foro privilegiado, de competência de julgamento de juízes de primeira instância. Segundo Moro, em seu despacho, "não deve o Judiciário ser o guardião de segredos sombrios. Além disso, a publicidade previne vazamentos ilegítimos, lamentáveis e de difícil controle" (CARVALHO, 2017).

A Odebrecht e a Braskem se declararam culpadas. A firmação do acordo resultou em diversos desdobramentos da Operação Lava Jato no mundo todo, em especial na América. Além do ex-presidente Temer e da cúpula do Congresso Nacional, são citados pelos delatores, nesse caso, quatro ex-presidentes da República: Dilma Rousseff, Luiz Inácio Lula da Silva, Fernando Collor de Mello e Fernando Henrique Cardoso. Os detalhes desse esquema constam de vários vídeos das delações de executivos e ex-executivos da empreiteira, incluindo o do empresário Marcelo Odebrecht.

Para exemplificar o fenômeno que pretendemos debater neste artigo, fizemos uma busca no site do jornal Folha de S.Paulo (escolhemos este veículo por ser, junto com $O$ Globo, o de maior alcance no país), usando os filtros "Odebrecht" e "Lava Jato", entre 11 e 12 de abril, quando o sigilo foi quebrado. A intenção era entender o tratamento dado às delações naquelas matérias. Elegemos essas datas porque foram emblemáticas por envolver um volume grande de delações divulgadas em um curto período de tempo, em um episódio marcante, do ponto de vista político, das investigações. Restringimos a busca a 24 horas, porque só nesse 
período foram encontradas 114 matérias, ou seja, não daríamos conta de analisar, para este artigo, um volume maior de reportagens. Devido ao fato de o mecanismo de busca no site do jornal $O$ Globo ser menos estruturado, não foi possível fazer com ele uma análise semelhante à realizada no site da Folha de S.Paulo.

O número de matérias encontradas no site da Folha nesse período (114) representa uma média de quase cinco matérias por hora. A busca foi feita na seção de política do site. Desse material, 44 (quase 40\%) têm no título a expressão "diz delator", com as variantes "relata" ou "afirma". Muitas matérias são iniciadas com o mesmo lide padrão, informando que os depoimentos foram liberados. Depois, havia a exposição de uma delação. No fim de todas as matérias, o mesmo texto padrão resumia o contexto, explicando brevemente o momento da Operação Lava Jato.

Das 114 matérias, pelo menos 52 são baseadas apenas em uma delação, com a resposta de alguém citado na denúncia. $\mathrm{O}$ lide começa relatando o conteúdo da fala de alguém, muitas vezes de forma afirmativa. Por exemplo, primeiro afirma-se algo ("Fulano recebeu R\$ 400 mil de propina") e depois é dito que a informação consta da denúncia de um delator. Outras 28 também são baseadas em delação, seguindo este mesmo modelo, porém sem resposta de ninguém citado. Há ainda oito matérias que se iniciam com as repercussões jurídicas de uma delação ou da operação, sem resposta de ninguém citado, e mais 12 com resposta. Pelo menos nove matérias são baseadas ainda em uma fala de alguém, que comenta uma delação ou a operação, como um todo. Por fim, cinco matérias apenas comentam algum movimento da operação ou curiosidades, como os apelidos dos denunciados.

Entre as 114 matérias nesse período, pelo menos 89 (78\%) são baseadas simplesmente em falas. Certamente, a análise merecia um período mais prolongado e um tratamento mais minucioso, mas estes dados já são interessantes para avaliar a corrida sobretudo no ambiente on-line, gerada para produzir matérias que se fundamentam apenas em um relato, sem analisar passado, presente e futuro da afirmação, ou seja, sem inserir a afirmação em um texto com historicidade 5 .

Esta análise pode ser articulada com outras pesquisas que analisam a cobertura da operação Lava Jato em veículos hegemônicos, sobretudo no jornal $O$ Globo, expondo uma tendência à seleção e à valorização de falas que reforcem a posição política do jornal, de oposição ao Partido dos Trabalhadores. Muito embora o jornal não admita essa posição,

\footnotetext{
${ }^{5}$ Cabe ponderar que o recorte neste artigo tem caráter ilustrativo e se insere em uma pesquisa maior sobre testemunho e jornalismo, com outras metodologias e referenciais teóricos, desenvolvidos na tese de doutorado da autora.
} 
ancorando-se em bandeiras de imparcialidade, a escolha política é clara e foi apontada, no contexto político da Lava Jato, por outros estudos.

Especificamente no caso do impeachment, Becker, César, Gallas e Weber (2016) analisaram o enquadramento de 12 capas dos jornais $O$ Globo, Folha de S.Paulo e $O$ Estado de S. Paulo em quatro episódios desse período, sendo eles: as manifestações a favor e contra o impeachment, a votação na Câmara e os encaminhamentos para o Senado. Utilizou-se, metodologicamente, a análise de conteúdo e de enquadramento. As autoras identificam uma polarização entre PT/Lula (associando a esse polo crise política e corrupção) e judiciário (atribuindo protagonismo ao juiz Sergio Moro e a outros órgãos do Judiciário) e indicam o enaltecimento dos atos pró-impeachment e o rebaixamento da importância das manifestações de apoio ao governo Dilma.

Segundo as autoras, na manchete do dia 14 de março 2016 do jornal O Globo, "Brasil vai às ruas contra Dilma e Lula e a favor de Moro", as manifestações pelo afastamento indicam o desejo nacional e promovem o juiz. As pesquisadoras argumentam que as capas concentram a retórica maniqueísta do "nós" contra "eles", em uma luta do bem contra o mal. Exemplos disso são o emprego frequente do adjetivo "brasileiros" para se referir aos manifestantes favoráveis ao impeachment e a construção de um discurso consensual em torno da condenação pública dos líderes petistas, isto é, dos inimigos do povo, em oposição ao juiz Moro, tratado como o grande aliado da população brasileira. Esse enquadramento ganharia reforço, segundo as autoras, no destaque ao número de pessoas presentes no protesto, o que, mais do que mera informação, quer indicar o fim do governo de Dilma Rousseff como a vontade soberana do povo. Identifica-se nas chamadas da capa um esforço desses jornais em torno da idoneidade do processo de impeachment e da culpabilização e do desgaste da imagem do governo petista.

Fernandes (2017) analisou, na capa do jornal $O$ Globo, 358 manchetes entre 12 de abril e 11 de maio de 2016, período de articulação da deposição da presidente Dilma. A partir das referidas notícias, foram realizados 414 enquadramentos em dez categorias. O exame do corpus foi realizado com base em Framing Analysis (GOFFMAN, 1974), com enfoque em medidas quantitativas. Segundo a autora, o enquadramento com maior número de matérias, com 33,5\% das chamadas, é o de Mobilização de Direita/Oposição, que engloba as movimentações da oposição no Congresso e da população contra a presidente, as matérias culpabilizando o governo pela situação que levou ao impeachment e, ainda, as tratativas para montagem do governo de Michel Temer. A autora chama a atenção para a desproporção em 
relação às ações do governo Dilma e de sua base de apoio no mesmo período, com apenas $5,7 \%$ das manchetes.

Em segundo lugar, com $22 \%$, estão as chamadas com a temática da corrupção. Têm presença predominante as matérias que envolvem políticos ligados ao governo e ao Partido dos Trabalhadores. A Crise Econômica foi responsável por 12\% das matérias publicadas na capa de $O$ Globo no período e, em alguma medida, estimulou a insatisfação contra o governo federal. A Ineficiência do Estado (7,9\%) e o Descrédito na Política $(7,2 \%)$ são outras duas temáticas presentes. $\mathrm{O}$ estudo sugere uma tendência de apoio à derrubada da presidente.

Shuen (2017) também analisou manchetes e chamadas dos jornais Folha de S.Paulo e O Globo, que citam Dilma ou Presidente/a ou Governo/Planalto ou Petista (para se referir a Dilma) no título. Foram 793 unidades textuais, de 27 de outubro de 2014 (dia seguinte à reeleição) a 13 de maio de 2016, dia seguinte à abertura do processo de impeachment no Senado. São 359 manchetes e chamadas da Folha e 434 de O Globo. As palavras mais associadas à presidente Dilma e seu governo nas manchetes e chamadas de ambos os jornais são categóricas: derrota (dez vezes tanto em $O$ Globo quanto na Folha), admitir (nove vezes em cada jornal), tentar (nove vezes em $O$ Globo), rombo (nove vezes em $O$ Globo e cinco na Folha), gasto e déficit (oito vezes na Folha, quatro em $O$ Globo), perder (sete vezes na Folha, cinco em $O$ Globo), pressão (seis vezes na Folha, quatro em $O$ Globo), negar (seis vezes na Folha, cinco em $O$ Globo), erro (seis vezes na Folha, dez vezes em $O$ Globo), defender (seis vezes na Folha, quatro em $O$ Globo), trapalhada (três vezes na Folha, não aparece em $O$ Globo). São palavras que conotam negatividade. A sigla PMDB aparece em 26 chamadas de $O$ Globo e em 11 da Folha. O termo oposição, associado a dados negativos para Dilma, aparece 11 vezes na capa de ambos os jornais.

As pesquisas chamam a atenção para uma tendência de construção de um discurso que reforce o argumento político dos veículos. Neste contexto, cabe ainda mais nos perguntar se o destaque e o tratamento dados às delações e às falas selecionadas não reforçariam um movimento político já em curso pelas empresas. Dentre tantas delações, por que umas são destacadas e outras não? Com que intuito são divulgadas? As falas e acusações podem servir como um prato cheio para um banquete com hora marcada e menu já selecionado. Além disso, sem tratamento ou contextualização, como vimos no caso das matérias analisadas do jornal Folha de S.Paulo, podem servir apenas como munição para quem deseja compartilhar textos que reforcem ideias preconcebidas. A delação e o testemunho que vão ao encontro da visão política de determinado leitor rapidamente são replicados nas redes, sem necessidade de cobrança por um aprofundamento da informação pelos meios. 


\section{Conclusão}

Quando analisamos as matérias do jornal A Folha de S.Paulo e percebemos a rapidez com que os testemunhos são transformados em matérias, sem contextualização, nos perguntamos sobre as mudanças nas práticas jornalísticas hoje, no sentido de uma perda do protagonismo do jornalista. Quando assume este papel de curador de exposições de falas, ele perde a oportunidade de enriquecer textos e apurações com seu brilho próprio, tanto do ponto de vista investigativo quando estilístico. Esta falta de contextualização que identificamos na divulgação dos testemunhos afeta seu significado, uma vez que não problematiza e não aprofunda - nem questiona - as afirmações. Isto traz riscos políticos, no sentido de oferecer um material bruto, não lapidado, de informações usadas para reforço de uma ou outra posição. Thaler, Sunstein e Balz (2010) defendem que a internet permite às pessoas viver em "casulos de informação ou câmaras de ressonância", que operam de acordo com uma dinâmica segundo a qual os indivíduos só tendem a acreditar naquilo que reforça suas crenças. As crenças, por sua vez, se apoiam, muitas vezes, em experiências transmitidas por meio dos relatos.

Jornalistas de redações do Rio de Janeiro (GERK, 2016) se queixam da reprodução de relatos sem contextualização, no sentido de criticar um "empobrecimento" da reportagem, o "carro-chefe" da prática jornalística, historicamente apoiada em um esforço de apuração. Na pressa de publicar, eles afirmam, muitas vezes apenas se reproduzem as falas. No contexto da Lava Jato, a partir de uma suspeita de tomada de posição de veículos que se dizem neutros e objetivos, conforme mostram estudos brasileiros (como os citados neste artigo), valeria uma nova pesquisa que mostrasse o destaque dado a determinados relatos, que vão ao encontro destas posições, e não a outros. Este artigo não contempla esta análise, mas aponta para a necessidade dela.

Muitos artigos em veículos jornalísticos se resumem à reprodução da informação da fonte, com a resposta da autoridade competente, ou a reprodução de uma fala de pessoa pública, sem polifonia ou análise sobre passado e possível desdobramento da situação. A verdade da experiência de cada um, transmutada sob a forma de imagens vistas, capturadas e partilhadas, produz um discurso desassociado de qualquer referencial. A compulsão pela fala desassociada de sentido profundo esvazia a capacidade de categorizar, de evoluir criativamente. Dificilmente há tempo e investimento na produção de conteúdos que marquem quando o trabalho se resume à administração de relatos. $\mathrm{O}$ testemunho costuma ter sentido 
mais amplo e profundo quando relacionado ao grupo do qual seu autor faz parte, depende do contexto do indivíduo em questão. A fala não está encerrada em si.

Lyotard (1986) definiu a pós-modernidade como o "estado da cultura após as transformações que afetaram as regras dos jogos da ciência, da literatura e das artes a partir do final do século XIX” (1986, p. 15). Haveria, segundo os pós-modernos, uma predileção atual pela eficácia tecnológica para o consumo, que pode ser também de pessoas e valores. $\mathrm{Na}$ conjuntura moderna, a verdade era encontrada pelo sujeito. Um sujeito diante do real que queria conhecer precisava olhar para seu fundamento, compreendê-lo, saber sua verdade e representá-lo. Na conjuntura pós-moderna, o real ainda existiria, evidentemente, mas teria perdido a capacidade de gerar grande interesse. As grandes narrativas do século XIX para legitimar o real teriam perdido credibilidade e levado consigo a importância de conceitos como fundamento, verdade, representação, sujeito. $\mathrm{O}$ valorizado agora passaria a ser não a busca de causas, mas a eficácia na produção de resultados a serem consumidos. D’Amaral (2010, p. 2) resume: "Tornou-se problemático continuar a dizer real, verdade, fundamento como se fossem coisas seguras". Eles fariam obstáculo à eficácia.

Haveria, nesse contexto, uma tendência ao relativismo, e não ao absoluto. A produção de sentido passaria ao consumo de informação. A ciência abriria mão da sua capacidade de determinar e provar o real para focar na eficácia. Os pós-modernos alegam que a história pertence à causa, ao passado, e que a relação de causalidade no presente não interessaria. D’Amaral (2010) explica que, embora ainda se espere que um telejornal ou um político falem a verdade, é preconizada a necessidade de levar em consideração os contextos, os pontos de vista. É claro que nenhum texto é imparcial e que a verdade absoluta não existe, mas a noção de imparcialidade usada como bandeira historicamente pelos jornalistas pressupõe um maior compromisso com a elaboração de um discurso mais abrangente, que explore diferentes pontos de vista ao adotar viés investigativo.

O jornalista, do ponto de vista histórico, era o sujeito dotado de autoridade por ser justamente quem presenciou cenas e investigou fatos para extrair deles uma versão mais fidedigna, explorando todos os "lados" de uma dada situação. Apesar de reconhecermos que esta classificação pode ser ingênua, pelos jogos de poder envolvidos na construção de uma narrativa, também não se pode ignorar que era - ou ainda é - a retórica utilizada pelas empresas de comunicação. Qual seria o papel do jornalista nesse novo contexto em que o interesse por um material jornalístico mais fidedigno se perde, a autoridade passa a ser de quem viveu e as narrativas tendem apenas a endossar a publicidade de certas visões já 
concebidas? Não parece haver mais o interesse de ao menos "vender" uma imagem de esforço de apuração quando as matérias reproduzem apenas um único relato.

Uma foto ou um relato precisariam ser encarados, assim, como rastros de fatos a serem destrinchados, compreendidos, em um movimento que convida o espectador a participar. O testemunho pode ser um caminho promissor para refletir e apreender como os acontecimentos sociais são construídos nos e pelos relatos midiáticos e pelos indivíduos que com eles interagem. Em Ricoeur (2007), o reconhecimento da condição histórica do ser humano implica atentar-se para as complexas relações com o passado, incluindo aí as diversas experiências da memória, e com o futuro, este na forma de expectativa. Nesse sentido, ele argumenta que o passado não pode ser interpretado como um acúmulo de acontecimentos acabados e inertes. Ele deve ser permanentemente problematizado. Assim, Ricoeur argumenta que é preciso reabrir o passado, reavivar nele as potencialidades irrealizadas, impedidas. É preciso, da mesma forma, destrinchar as falas, deslocá-las, interpretá-las.

O passado da notícia tendia a ser oferecido como "eu, jornalista, estive lá e fui testemunha da história". Essa rememoração também parecia induzir a um congelamento do passado, na medida em que ele é tratado como um acúmulo de acontecimentos, como se a história estivesse disponível, mas sem que ela, num movimento contrário, também fosse testemunha e agente das mudanças sofridas pelo próprio jornalismo. Não se trata, pois, de lutar por colocar o poder de engessar o passado novamente nas mãos do jornalista. Trata-se, ao contrário, de fazer um esforço para estranhar presente e passado, colocando mais perguntas e relacionando mais elementos. O testemunho não pode ser considerado apenas um registro objetivo de uma experiência. O discurso, inclusive o jornalístico, altera a realidade, uma vez que a narrativa inventa o mundo, no sentido de recriá-lo. No caso da Operação Lava Jato, é difícil distinguir em que medidas o próprio discurso jornalístico afetou o rumo dos acontecimentos que levaram à derrubada da presidente, por exemplo.

O grande paradoxo do testemunho: se só é possível narrar recorrendo à imaginação e à memória, o testemunho pode ser contaminado por essa dose de imaginação e ficção. Isto precisa ser sempre levado em consideração. Não é que as delações da Lava Jato não devessem, necessariamente, ser divulgadas e conhecidas. Mas é o tratamento simplista e sem questionamento que se dá às falas que empobrece a qualidade jornalística.

Além disso, não se pode esquecer que a possibilidade de narrar carrega ainda a potência do que não é narrável e, sendo assim, “o testemunho vale essencialmente por aquilo que nele falta" (AGAMBEN, 2008, p. 43). Nessa perspectiva, o testemunho é também uma construção de linguagem que se configura na tensão entre o que se pode dizer e aquilo que de 
fato é dito. O que foi deixado de fora? O que foi escolhido? É preciso interrogar-se também sobre a natureza deste não testemunhado, do não dito. Assim, o relato transmite tanto as provas e evidências de seu trajeto como os desvios e mistérios encontrados. Um relato é um mapa, que leva para muitos caminhos, explorados ou não naquela fala. É preciso entender estas rotas.

\section{Referências bibliográficas}

AGAMBEN, G. O que resta de Auschwitz. São Paulo: Boitempo Editorial, 2008.

BECKER, C.; CÉSAR, C. M.; GALLAS, D.; WEBER, M. H. Manifestações e votos sobre impeachment de Dilma Rousseff na primeira página de jornais brasileiros. Alaic - Revista Latinoamericana de Ciencias de la Comunicación, São Paulo, v. 13, n. 24. p. 96-113, jan.-jun. 2016.

CARVALHO, C. Moro também levanta sigilo de depoimentos de delatores da Odebrecht. O Globo, Rio de Janeiro, 12 abr. 2017. Disponível em: https://oglobo.globo.com/brasil/morotambem-levanta-sigilo-de-depoimentos-de-delatores-da-odebrecht-21197198. Acesso em: out. 2017.

D'AMARAL, M. T. Sobre tempos e história: O paradoxo pós-moderno. In: SANTORO, F.; FOGEL, G.; AMARAL, G.; SCHUBACK, M. C. (Org.). Pensamento no Brasil - Emmanuel Carneiro Leão. Rio de Janeiro: Hexis / Fundação Biblioteca Nacional, v. 1, 2010, p. 351-369.

DE LA BRUYÈRE, J. Les caractères de Theophraste traduits du grec, avec les caractères, ou, les moeurs de ce siècle. Paris: Bookking International, 1847.

DELEUZE, G. Proust e os signos. 2. ed. Trad.: Antonio Piquet e Roberto Machado. Rio de Janeiro: Forense Universitária, 2003.

FERNANDES, R. A corrupção de hoje e o comunismo de ontem: a imprensa e suas temáticas na criação de consensos que antecedem os golpes. In: $\mathbf{4 0}^{\circ}$ Congresso Brasileiro de Ciências da Comunicação, 04-09/09/2017. Anais. Curitiba: Intercom - Sociedade Brasileira de Estudos Interdisciplinares da Comunicação, 2017. Disponível em: http://portalintercom. org.br/anais/nacional2017/resumos/R12-1468-1.pdf. Acesso em: out. 2017.

FONSECA, V.; KUHN, W. Jornalista contemporâneo: apontamentos para discutir a identidade profissional. Intexto, Porto Alegre, UFRGS, v. 2, n. 21, p. 57-69, jul.-dez. 2009.

GERK, C. Jornalismo e público: reconfigurações no contexto digital. WhatsApp do Extra como ferramenta histórico-tecnológica. 2016. Dissertação (Mestrado em Comunicação e Cultura) Escola de Comunicação, Universidade Federal do Rio de Janeiro (UFRJ/ECO), Rio de Janeiro, 2016.

GOFFMAN, E. Frame Analysis. Nova York: Harper \& Row, 1974.

KOSELLECK, R. Futuro passado - contribuição à semântica dos tempos históricos. Rio de Janeiro: Contraponto, 2006.

LYOTARD, J-F. O pós-moderno. Rio de Janeiro: José Olympio, 1986.

RICOUER, P. A memória, a história, o esquecimento. Campinas SP: Editora da Unicamp, 2007. 
SARLO, B. Tempo passado: cultura da memória e guinada subjetiva. São Paulo: Companhia das Letras, 2007.

SODRÉ, M. A narração do fato: notas para uma teoria do acontecimento. Petrópolis: Vozes, 2009.

SHUEN, L. O Governo, a Imprensa e a Narrativa: Um estudo sobre o Adversarial Journalism nas capas de $O$ Globo e Folha de S.Paulo durante a crise do Governo Dilma. In: $\mathbf{4 0}^{\circ}$ Congresso Brasileiro de Ciências da Comunicação, 04-09/09/2017. Anais. Curitiba: Intercom - Sociedade Brasileira de Estudos Interdisciplinares da Comunicação, 2017. Disponível em: http://portalintercom.org.br/anais/nacional2017/resumos/R12-2963-1.pdf. Acesso em: out. 2017.

THALER, R. H.; SUNSTEIN, C. R.; BALZ, J. P. Choice Architecture. SSRN. 2 abr. 2010. Disponível em: https://ssrn.com/abstract=1583509. Acesso em: out. 2017.

VAZ, P.; SANTOS, A.; ANDRADE. P. H. Testemunho e subjetividade contemporânea: narrativas de vítimas de estupro e a construção social da inocência. Lumina, Juiz de Fora, v. 8, n. 2, 29 jan. 2014, p. 1-33. Disponível em: https://periodicos.ufjf.br/index.php/lumina/article/ view/21162. Acesso em: out. 2017.

ZELIZER, B. Covering the Body: the Kennedy assassination, the media and the shaping of collective memory. Chicago: The University of Chicago Press, 1992. 